\title{
Seminario sobre imprenta y librería en 2010
}

\author{
Por Mònica Baró
}

Baró, Mònica. "Seminario sobre imprenta y librería en 2010". En: El profesional de la información, 2008, julio-agosto, v. 17 , n. 4 , pp. 468-470.

DOI: 10.3145/epi.2008.jul.16

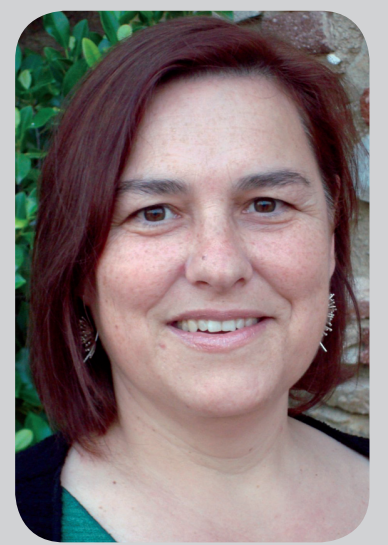

Mònica Baró Llambias es diplomada en biblioteconomía y documentación, licenciada en historia y doctora en documentación por la Universitat de Barcelona. Trabaja en los ámbitos de historia de la edición y bibliotecas escolares. Es profesora en la Facultat de Biblioteconomia i Documentació de dicha universidad, donde imparte clases de Historia de la producción documental, y también de Biblioteca escolar en el Màster Oficial de Biblioteques escolars, del que es coordinadora.

EN SU TERCERA EDICIÓN, el pasado 29 de mayo tuvo lugar el Seminario de l'Aula Jordi Rubió i Balaguer de la Facultat de Biblioteconomia i Documentació de la Universitat de Barcelona. En esta ocasión estuvo dedicado a presentar y debatir el rol de la edición y la librería en el contexto digital bajo el título "Impremta $i$ llibreria a la Barcelona digital del 2010"

El título remite al de una obra del propio Jordi Rubió i Balaguer, Impremta i llibreria a Barcelona (1474-1553), con el doble motivo de homenajear a su autor y de establecer un punto de partida para el análisis de los cambios de los sectores implicados en la producción y difusión del libro.
La primera intervención corrió a cargo de Josep Massot i Muntaner, director de la editorial Publicacions de l'Abadia de Montserrat, decana de la edición en España, puesto que ya editaba en 1499. Massot glosó la figura de Jordi Rubió, como erudito y especialista en distintos ámbitos de la cultura. De entre todas sus facetas destacó la de sistematizador del sistema bibliotecario catalán de principios de siglo a partir del conocimiento directo de las bibliotecas alemanas, y especialmente en base a las innovaciones en los servicios públicos de EUA. A la vez, de entre su variada producción destacó sus estudios sobre bibliología y centró su atención en la obra Documentos para la historia de la imprenta y la librería en Barcelona (1474-1553), publicada en 1955 por el Gremi d'Editors, Llibreters i Mestres Impressors, para conmemorar los cuatrocientos años de la creación de la Confraria de Sant Jeroni de libreros de la ciudad de Barcelona. Precisamente la introducción a esta ingente obra -que aporta transcripciones de 523 documentos, realizadas en colaboración con Josep M. Madurell i Marimón-, fue traducida al catalán y editada como volumen independiente por la entonces Escola

\section{"Mascarell sentenció} el fin de la imprenta tal como la describe Rubió y comparó la revolución que se avecina con la que significó el propio libro en su momento"

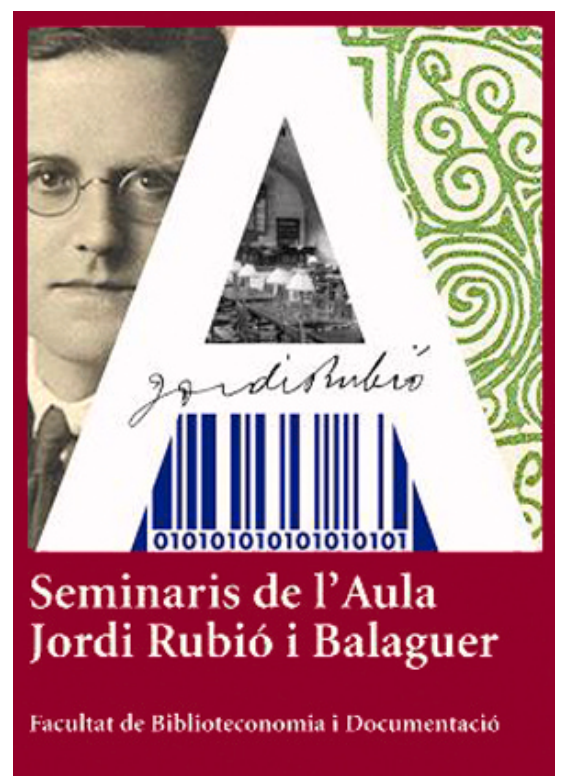

Universitària Jordi Rubió i Balaguer de Biblioteconomia i Documentació en 1986 con el título que indicábamos anteriormente.

En esta introducción, verdadera monografía sobre el tema, Rubió describía el incipiente mundo de la edición y la librería, dando voz a los registros documentales y aportando luz a sus aspectos más oscuros. De su mano visitamos los talleres de imprenta y librería, descubrimos las múltiples ocupaciones de quienes trabajan en ellos y sus relaciones laborales e incluso familiares, para establecer de qué modo los antiguos oficios se adaptan a los nuevos tiempos, buscando las nuevas oportunidades de negocio y ampliando el ámbito de sus intereses. Así, Rubió establece cómo los libreros-encuadernadores se van convirtiendo en editores y contratan el trabajo de los recién llegados impresores, alemanes en su mayoría, para surtir sus tiendas, y también 
cómo los poderes, Iglesia y Estado, descubren en la imprenta un potencial insospechado y se convierten a su vez en editores.

El segundo ponente, Ferran Mascarell, ex-consejero de Cultura de la Generalitat de Catalunya y en este momento director de la división de audiovisuales de $R B A$, entroncó las aportaciones de Rubió con las más actuales de autores como Roger Chartier o Alberto Manguel y especialmente con la reciente aportación de Joaquín Rodríguez en su Edición 2.0 - Los futuros del libro, y esbozó los principales cambios derivados de la generalización del mundo digital en el sector de la edición.

Sentenció el fin de la imprenta tal como la describe Rubió, muy parecida a la que él mismo conoció, y comparó la revolución que se avecina con la que significó el propio libro en su momento, propiciando cambios en el sistema de producción pero también en su comercialización. Cambios que conectan especialmente con los usos y las prácticas de los más jóvenes, lectores o no, para quienes la cultura se vehicula a través de la Red, de la que son usuarios en unos elevadísimos porcentajes, y que a la vez les facilita nuevos espacios y una gran visibilidad para sus creaciones. Este nuevo concepto de autor, que ahora se extiende a todo aquel que "publica" en la Red, está en la base de muchas de estas modalidades de uso, puesto que en cierto modo quien aporta contenidos a la comunidad se reviste del derecho a utilizar sin restricciones los aportados por los demás autores.

Entre las múltiples virtudes de la Red, Mascarell mencionó las de la democratización de la información, que permite entender mejor el mundo en el que vivimos, pero también la de incrementar la confianza en sí mismos por parte de los usuarios que ahora tienen mayor posibilidad de elección y de interacción con la información. En este sentido esbozó el final del enciclopedismo tal como lo hemos conocido, sustituido por las nuevas obras colaborativas como la Wikipedia. Y también indicó que los cambios afectan y afectarán todavía más al sector de la prensa periódica, no tanto en la pérdida de lectores como en el cambio de formato: de una función informativa pasará a dedicar más espacio a la opinión.

\section{Mesa redonda}

A continuación se inició la mesa de debate coordinada por Mònica Baró, profesora de la Univ. de Barcelona, con la participación de Ciro Llueca, coordinador de Padicat (Patrimoni Digital de Catalunya) de la Biblioteca de Catalunya, Imma Bellafont, presidenta del Gremi de Llibreters de Barcelona $i$ Catalunya, y Lluís Bonet, profesor de la Univ. de Barcelona y coordinador del Màster de Gestió Cultural.

El coloquio se inició con un intercambio de opiniones en torno al tiempo de convivencia de los distintos tipos de libro -impreso y digital- que se relacionó con la resistencia al cambio y también con los distintos usos: para la consulta de datos se afianzará el entorno digital, mientras que la lectura introspectiva seguirá por un tiempo realizándose a través del papel. Se apuntó que el futuro del libro pasa en determinadas modalidades por su "deconstrucción", lo que va a permitir al lector editar los contenidos a la medida de sus necesidades.

Este proceso está ya en marcha $\mathrm{y}$, por ejemplo, para preparar un viaje ya no es necesaria una guía impresa puesto que el propio viajero puede encontrar en la Red los datos actualizados, las lecturas literarias relativas al lugar visitado que podrán acompañarlo en su periplo y las opiniones de quienes lo han realizado anteriormente, y reunirlos en una nueva obra personalizada. Asimismo un blog puede sustituir a una edición en papel de artículos de un autor y el mismo lector puede seleccionar y recopilar de distintas fuentes los que prefiere.

\section{"Para la consulta de datos se afianzará el entorno digital, mientras que la lectura introspectiva seguirá por un tiempo realizándose a través del papel"}

Este cambio parece que no afectará de igual modo a las obras de estructura lineal como son las novelas, aunque probablemente se leerán en formato digital como recurso para optimizar el espacio. Para este cambio de formato no existen en la actualidad dificultades tecnológicas, como demuestra la comercialización de dispositivos de $e$-book, pero sí hay muchos problemas relacionados con la gestión de los derechos de autor.

También se planteó un paralelismo entre el mundo de la edición musical, que se ha modificado radicalmente en los últimos años. En este sentido, el mundo editorial se caracteriza por un mayor conservadurismo generado por un menor volumen de negocio, y por desarrollarse en un entorno cultural muy protegido, mientras que el mundo de la edición musical, mucho más joven y más dinámico, se está adaptando más rápidamente al contexto digital.

En este nuevo entorno Mascarell afirmó que los libreros deberán enfatizar su papel de mediadores entre libros y lectores, y tan pronto como se generalicen las máquinas de impresión instantánea, adquirirán de nuevo el papel de editores que tuvieron en los inicios de la imprenta. No obstante, Imma Bellafont opinó que este escenario todavía era una utopía, y que en la actualidad debería caminarse hacia una mayor cooperación entre los 
distintos agentes del libro. Como ejemplo apuntó que en la actualidad el sector no dispone de recursos compartidos y que un librero no puede saber si de determinado título existen ejemplares disponibles, ni en la propia editorial, ni en las distribuidoras ni tampoco en otras librerías. En esta línea especificó que también sería necesaria una mayor colaboración con las bibliotecas.

En cuanto a las bibliotecas se planteó el conflicto definido por Chartier entre pérdida y exceso. Ciro Llueca especificó que ciertamente la época de la obsesión recopilatoria parece superada y que en la actualidad se tiene muy en cuenta la difusión de los contenidos además de su preservación. En relación con este tema, se trabaja muy activamente en conservar los recursos electrónicos como webs y blogs.

Todos los participantes coincidieron en señalar que el mercado y en especial el consumo se erigirán más que nunca en árbitros de las decisiones a tomar en cuanto a la transferencia de contenidos a los nuevos soportes y entornos. Josep Massot puso como ejemplo el proyecto Google Búsqueda de Libros, al que se han adherido las principales bibliotecas catalanas pero también muchas editoriales, como la que él dirige, que han facilitado la digitalización de sus fondos libres de derechos. Otro ejemplo es el portal Quiosc. cat, desde el que pueden descargarse a precios reducidos algunas de las principales revistas en catalán. En ambos casos la tecnología contribuye a facilitar el acceso a contenidos que difícilmente van a ser reeditados en formato tradicional debido a los elevados costes de producción.

Finalmente, Lluís Bonet planteó la paradoja que se da en la actualidad: a mayor oferta y mayor democratización de acceso a los contenidos, mayor concentración

\section{"El mercado y el consumo se erigirán en árbitros en la transferencia de contenidos a los nuevos soportes y entornos"}

del consumo en unos determinados títulos, que se configuran como verdaderos referentes de la nueva cultura popular.

En resumen, el Seminario permitió reflexionar sobre el momento de cambio que estamos viviendo en el mundo del libro y de su producción, a partir de un profundo conocimiento de los procesos que se han dado en el pasado y de su aplicación en el contexto actual.

Mònica Baró, Facultat de Biblioteconomia i Documentació, Universitat de Barcelona.

baro@ub.edu

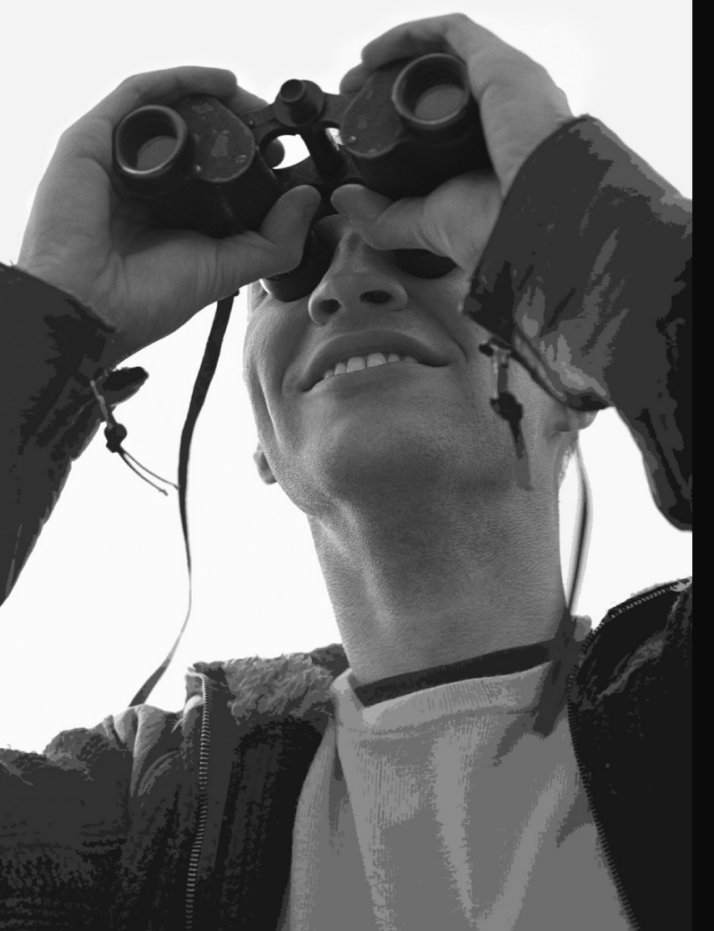

\section{MÁSTER EN DOCUMENTACIÓN DIGITAL}

Máster y Programas de posgrado online

Arquitectura de la información en sitios web. - Organización de la información y sistemas de gestión de base de datos. . Buscadores y posicionamiento web. . Documentación audiovisual. - Web 2.0 (nuevo). - Archivística digital. - Gestión de contenidos y gestión del conocimiento. - Repositorios y bibliotecas digitales (ampliado). . Usabilidad.

Dirección: Cristòfol Rovira y Lluís Codina

Calendario: del 9 de octubre de 2008 al 30 de junio de 2009.

www.documentaciondigital.org

\section{MÁSTER EN BUSCADORES \\ MARKETING Y POSICIONAMIENTO}

Máster y Programas de posgrado online

- Fundamentos. - Posicionamiento en Buscadores. - Marketing en Buscadores. - Vigilancia Tecnológica. • Recuperación de la Información. • Buscadores especializados.

Dirección: Cristòfol Rovira y Lluís Codina

Calendario: del 13 de noviembre de 2008 al 30 de junio de 2009.

www.masterenbuscadores.com

\section{Colaboran:}

Observatorio de Comunicación Científica · UPF Instituto Universitario de Lingüística Aplicada - UPF DOC 6 Consultores de Recursos de Información 